\title{
Comparação de tamanhos e distâncias de subparcelas aplicadas em processo de amostragem por conglomerado
}

\author{
Oberdan Müller M. das FLORES ${ }^{1}$, Waldenei Travassos de QUEIROZ², João Guimarães PINHEIRO², \\ Francisco de Assis OLIVEIRA ${ }^{4}$, Arlete MORAES 5 , Mário Diego Rocha VALENTE 6
}

\begin{abstract}
RESUMO
Realizou-se um estudo com unidades amostrais conglomeradas de estrutura cruzada usando banco de dados de inventário florestal 100\% de uma Unidade de produção Anual (UPA-08), localizada na fazenda Martins no alto Pacajá, Município de Portel, Estado do Pará, para estudar os efeitos da variaçáo entre e dentro dos conglomerados usando como referência três variáveis resposta: i) VT = Volume total de madeira das 77 espécies florestais encontradas na área de estudo; ii) VO = Volume Total das 10 espécies florestais de maior ocorrência e volume na área de estudo; e iii) VC = Volume Total das 10 espécies florestais mais comercializadas pela empresa Cikel, tendo como objetivo determinar o tamanho e a distância ideal de subparcelas a partir do Método da Curvatura Máxima, uma vez definido o tamanho, sua área é fixada e então são estudadas cinco diferentes valores para determinar a distancia ideal do centro do conglomerado até as subparcelas e entre as mesmas. Os resultados permitiram inferir que o tamanho de subparcela 0,10 ha, a distância de $50 \mathrm{~m}$ entre as subparcelas, e a estrutura cruzada com 8 (subparcelas) são eficientes para estimar os parâmetros estudados.
\end{abstract}

PALAVRAS-CHAVE: Inventário florestal; Amostragem por conglomerado; Tamanho de parcela; Correlaçáo intraconglomerado; Estrutura amostral.

\section{Comparison of sizes and distances of subplots applied in the process of cluster sampling.}

\section{ABSTRACT}

We conducted a study with sample units of conglomerate structure using cross-database of forest inventory $100 \%$ of Annual Production Unit (APU-08), located at the Top Pacajá Martins farm, municipality of Portel-PA to study the effects of variation between and within clusters with reference to three response variables they were: i) VT = Total volume of wood of 77 tree species found in the study area, ii) $\mathrm{VO}=$ Total Volume of the 10 most frequent tree species and volume in the study area and, iii) $\mathrm{Vt}=$ Total volume of 10 forest species Cikel more commercialized by the company we aimed to determine the ideal size and distance of plots from the Method of Maximum Curvature, once defined the size, its area was fixed and then there was tested five different values to determine the ideal distance from the center of the conglomerate to the plots and between them. Results showed that the size of 0.10 ha plot, the distance of $50 \mathrm{~m}$ between plots, and cross-structure with 8 subplots are efficient for estimating the parameters.

KEYWORDS: Forest inventory; cluster sampling, size of subplot; intraclass correlation; sample structure.

\footnotetext{
${ }^{1}$ Engenheiro Florestal, M. Sc. em Ciências Florestais, IFPA, Belém, PA, Brasil - muller30@gmail.com

2 Professor Adjunto, Dr., Instituto de Ciências Agrárias, UFRA, Belém, PA, Brasil - waldenei.queiroz@ufra.edu.br

${ }^{3}$ Estatístico, M. Sc. em Ciências Florestais, UFRA, Belém, PA, Brasil - jgp111@ig.com.br

${ }^{4}$ Professor Associado, Dr., Instituto de Ciências Agrárias, UFRA, Belém, PA, Brasil - fdeassis@ufra.edu.br

${ }_{5}^{5}$ Professora Associada, M. Sc., Pró-reitora de administração, Universidade Federal do Oeste do Pará, Santarém, PA, Brasil - arlete.ufra@yahoo.com.br

${ }^{6}$ Estatístico, Esp., Programa de Pós-Graduação em Bioestatística, UFPA, Belém, PA, Brasil - mariodiego@click21.com.br
} 


\section{INTRODUÇÃO}

$\mathrm{Na}$ Amazônia brasileira, os primeiros trabalhos técnicos sobre inventário florestal foram realizados na década de 1950, por meio de levantamentos realizados pela missão da Food and Agriculture Organization of the United Nations (FAO), em parceria com Superintendência do Plano de Valorização Econômica da Amazônia (SPVEA), antecessora da Superintendência do Desenvolvimento da Amazônia (SUDAM) (Sudam 1974).

Conforme Péllico Netto e Brena (1997), os inventários florestais são classificados em função dos objetivos a serem alcançados, da abrangência, da maneira de obtençáo dos dados, da abordagem da população no tempo e do grau de detalhameto dos resultados. Advertem, ainda, que no processo de inventário é necessario enfatizar a questáo da representatividade amostral e a sua validade estatistíca. Lima et al. (2007), Oliveira et al. (2009), Rossetti (2002), Zanon e Storck (2000), estudaram o tamanho ótimo de parcelas em processos de amostragem a partir de diversas técnicas entre elas destacam-se a correlação intraclasses para estudo de espécies vegetais perenes, o coeficiente de correlação entre diferentes culturas e o método da curvatura máxima modificado.

Muniz et al. (2009) advertem que apesar dos trabalhos realizados, envolvendo o tamanho ótimo de parcelas, tenham sido desenvolvido, em seus primordios, para culturas agricolas, a metodologia pode ser utilizada, com os devidos cuidados, para especies florestais.

Segundo Higuchi et al. (1982), o tamanho de parcelas comumente usado, para regióes de florestas tropicais como a Amazônia, é de $2500 \mathrm{~m}^{2}$ com forma retangular, para inventários com mensuração de DAP (diâmetro à altura do peito) acima de $20 \mathrm{~cm}$, estudos posteriores mostraram que parcelas de 20x50 (1000 $\left.\mathrm{m}^{2}\right)$ são mais eficientes estatisticamente. Vianna et al. (2010), estudaram em área de floresta ombrófila densa no alto Pacajá, município de PartelPA, o tamanho ótimo de parcela para estimativa de estoque de carbono e determinaram que o tamanho mais eficiente foi de $2000 \mathrm{~m}^{2}$.

Cavalcanti et al. (2009) estudaram diferentes tamanhos de unidades amostrais, no município de Sena Madureira, no Estado do Acre, em área de floresta ombrófila densa, tendo como variável resposta o volume total de madeira e com base no coeficiente de variação estabeleceu que o tamanho ideal de unidade amostral é 0,75 ha para a área de estudo, o que corrobora com outros trabalho realizados no bioma Amazônia.

Mello e Scolforo (2000) afirmam que existem vários procedimentos para inventariar áreas de florestas nativas, e ou plantadas, porém na América do Sul são feitas poucas referências sobre a eficiência desses procedimentos, principalmente quando se compara o processo de amostragem por conglomerados com o processo de amostragem simples ao acaso, para florestas nativas.

Brena (1996) propôs as bases para a realização de um Inventário Florestal Nacional (IFN) baseado no método de amostragem por conglomerados com oito subunidades com área de $1000 \mathrm{~m}^{2}$ para locais de fácil acesso na Amazônia brasileira com a finalidade de garantir a utilização sustentável dos recursos florestais.

Vieira e Couto (2001) estudaram o tamanho e número de parcelas localizadas no bioma Mata Atlântica no Parque Estadual de Carlos Botelho, na região sul do Estado de São Paulo, e concluíram que parcelas pequenas e amplamente distribuídas sobre uma determinada área captam melhor a variação da floresta do que parcelas compridas, e que o tamanho das parcelas em relaçáo às espécies mostraram grande variação.

Para Queiroz et al. (2011), devido à grande divergência de resultados encontrados na literatura, mais trabalhos sobre o processo de amostragem por conglomerados necessitam ser realizados, por isso o Brasil precisa estabelecer um sistema de Inventário Florestal Nacional (IFN), visando determinar as condiçóes científicas e técnicas necessárias para adoção de políticas públicas que resultem simultaneamente no desenvolvimento econômico-social, e na conservação ambiental.

Assim sendo, na busca de ampliar os conhecimentos a respeito do processo de amostragem por conglomerados, esta pesquisa visa responder a partir do confronto da variação entre os conglomerados e a variaçáo entre subparcelas dentro dos conglomerados qual o tamanho e a distância ideal entre subparcelas, visando tornar o inventário florestal mais prático, com a melhor eficiência estatística para a estimativa dos parâmetros estudados.

\section{MATERIAL E MÉTODOS}

A área em estudo é denominada Unidade de Produção Anual 08 (UPA 08), destacada conforme Figura $1^{1}$, cuja área é de 1400 ha, com ocorrência de 77 espécies florestais, e 28834 indivíduos (DAP $\geq 30 \mathrm{~cm}$ ), localizada na fazenda Martins, pertencente ao grupo Martins Agropecuária S/A, sendo arrendada para fins de exploração florestal sustentável pela empresa Cikel Brasil Verde Madeira Ltda, no Município de Portel, Estado do Pará, localizada nas coordenadas geográficas Long: 50¹8'19,27”W e Lat: 3¹2’34,69”S e Long: 49॰49'50,17"W e Lat: 2044'45,79”S. (Ferreira et al. 2009).

1 - Esta figura foi gentilmente cedida para este estudo pela empresa madeireira CIKEL BRASIL VERDE MADEIRAS LTDA. e sua reprodução em revista ou artigo científico esta autorizada. 


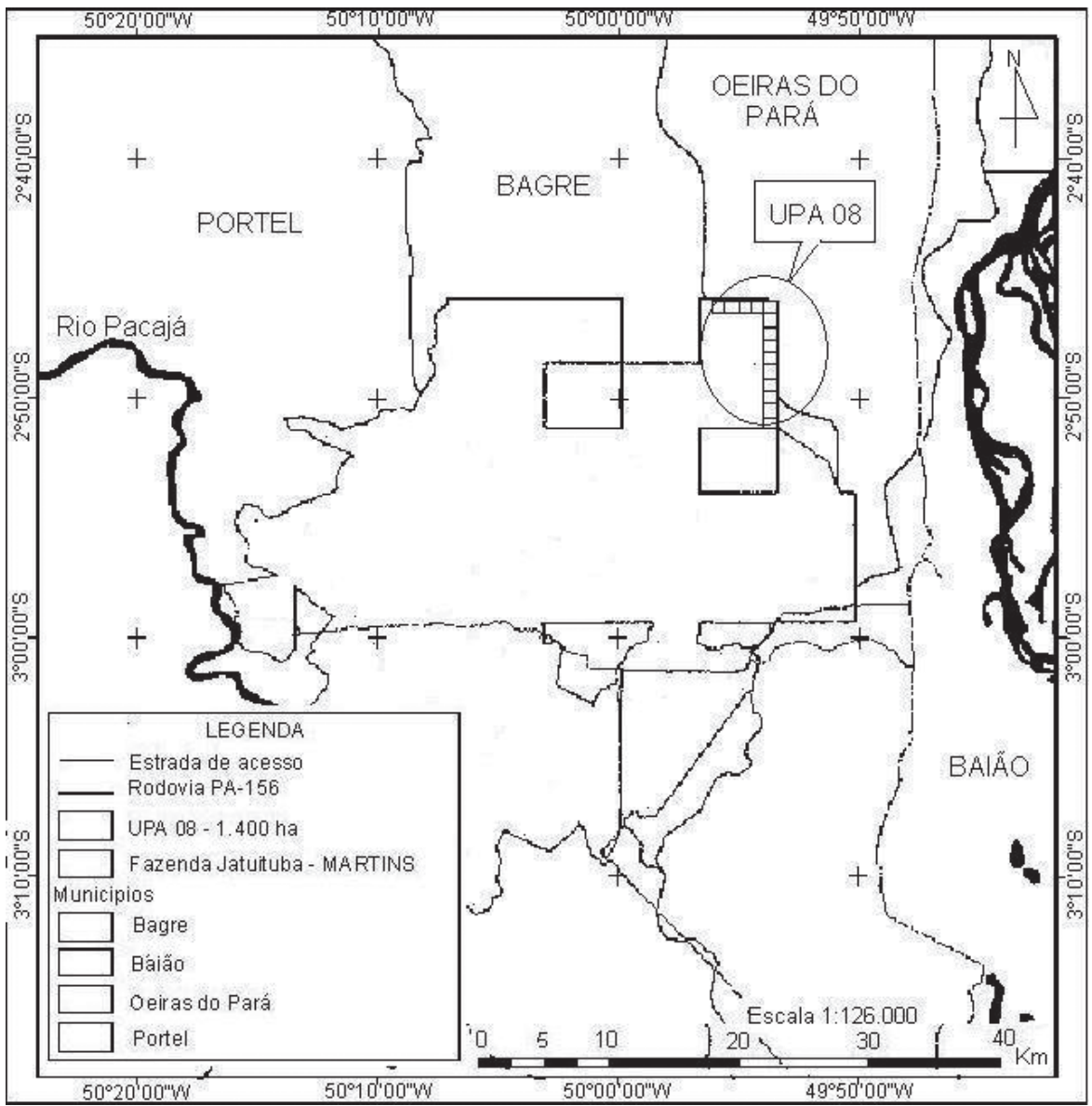

Figura 1 - Localização da área de estudo e área amostrada.

De acordo com a classificaçáo de Köppen, o clima da regiáo é tropical úmido (Amw), caracterizado por apresentar chuvas do tipo monçáo, isto é, quando apesar de oferecer uma estaçáo seca de pequena duração, possui umidade suficiente para alimentar a floresta tropical. Mantém elevados índices pluviométricos (cerca de $2.400 \mathrm{~mm}$ de chuva), alta temperatura média do ar $\left(26^{\circ} \mathrm{C}\right)$, e umidade relativa superior a $85 \%$ (Radam 1974).

\section{Inventário Florestal 100\%}

Os dados do inventário florestal 100\% da área de estudo, utilizados nesta pesquisa foi realizado por Ferreira et al. (2009) para fins de exploração florestal de forma sustentável pela empresa CIKEL BRASIL VERDE MADEIRAS LTDA, a partir de Diâmetro à Altura do Peito (DAP) maior ou igual a $30 \mathrm{~cm}$ das espécies consideradas comerciais, potênciais e estoque consideradas pela empresa. Este inventário revelou que as espécies comerciais apresentaram volumes de 17 a 50 $\mathrm{m}^{3} \mathrm{ha}^{-1}$, a partir de $50 \mathrm{~cm}$ de diâmetro sendo essas espécies de madeiras pesadas intermediária com maior ocorrência.
Entre as espécies comerciais mais importantes observadas na região, destacam-se: Maçaranduba (Manilkara huberi), Maparajuba (Manilkara paraensis), Angelim vermelho (Dinizia excelsa). Ipê (Tabebuia serratifolia), Cupiuba (Goupia glabra), Piquiá (Caryocar villosum), Tauari (Couratari sp.), Acapú (Vouacapoua americana), Jatobá (Hymenea courbaríi) Timborana (Piptadenia suaveolens) e Faveiras (Parkia spp). Vale ressaltar que a área apresentou grande quantidade de Angelins (Dinizia spp.) com 1512 indivíduos, sendo um dos volumes mais representativos $\left(0,62 \mathrm{~m}^{3} \mathrm{ha}^{-1}\right)$.

A localização de cada árvore inventariada na UPA - 08 foi realizada anotando-se em ficha de campo a posiçấo das árvores no sentido da "picada" (Norte - Sul) tendo com referência as distâncias em metros tomadas nos eixos X e Y. Posteriomente esses coordenadas foram inseridas em software de informação geográfica (ArcGis 9.2) para gerar um banco de dados do inventário florestal $100 \%$ contendo shape ${ }^{2}$ de pontos com a posiçáo real de cada árvore no espaço, e ainda uma tabela de

2 - Shape: São arquivos do ArcGis contendo atributos de objetos do mundo real, como coordenadas geográficas, estradas, acidentes geográficos, etc..., sendo representado por pontos, linhas e polígonos. 
atributos com os campos: nome da espécie, Circunferência à Altura do Peito (CAP), Altura $(\mathrm{H})$ e posição X e Y. Os campos $\mathrm{CAP}$ e Altura $(\mathrm{H})$ que foram usadas para obter o volume total de madeira por espécie a partir de uma equação de volume ajustada para a área.

\section{Equação utilizada no cálculo dos volumes das árvores}

Devido a AMF MARTINS não possuir até o início deste estudo uma equação de volume para estimar a volumetria da área, decidiu-se entáo utilizar o modelo ajustado ajustado por Ferreira et al. (2009) para a AMF Rio Capim, que fica a uma distância média de $250 \mathrm{Km}$ da área de estudo. possuindo caracteristica florísticas semelhantes. O modelo escolhido foi de Spurr. representado pelo modelo não linear:

$$
\mathrm{V}=\mathrm{b}_{\mathrm{o}}+\mathrm{b}_{1} \mathrm{x} \mathrm{d}^{2} \mathrm{xh} .
$$

Em que V: Volume estimado; $b_{0}$ : constante, que representa a interceptação da reta com o eixo vertical; $b_{1}$ : constante, que representa a declividade da reta; d: diâmetro e h: altura comercial.

Este modelo foi escolhido por apresentar um bom conjunto de indices: $r^{2}=0,97 ; s(\bar{x})=0,48 ; F=7619,90 ; C V \%=10,52$; $\mathrm{P}=0,000$. Em que $\mathrm{r}^{2}$ : coeficiente de determinaçấo; $\mathrm{s}(\overline{\mathrm{x}})$ : erro padrão de estimativa; $\mathrm{F}$ : valor da estatística do teste $\mathrm{F}$; $\mathrm{CV}$ : coeficiente de variação; p: nível descritivo. Após o processo de ajustamento obteve-se o seguinte modelo: $\mathrm{V}=-0,0152+$ $0,000052 \mathrm{xd}^{2} \mathrm{xh}$, em que V: Volume estimado; d: diâmetro; h: altura comercial. Utilizou-se este modelo para estimar a volumetria da base de dados do inventário florestal $100 \%$ da UPA-08 da AMF Martins.

\section{Processamento dos dados}

A instalaçâo dos conglomerados foi realizada utilizandose o Sistema de Informação Geográfica ArcGis 9.3, com as extensôes ET Hawths Tools, assim como ferramentas de edição vetorial, para a criação do "grid" (grade) de 10x10 $\mathrm{m}$ para orientar a alocação dos conglomerados no shape da UPA 08, conforme Figura 1. Posteriormente, realizou-se a coleta dos dados da populaçáo e das amostras a partir da ferramenta de uniáo espacial (Joins e Relates) para unir os dados do inventário florestal 100\% com os shapes das unidades secundárias dos conglomerados, exportando-se assim as informaçóes coletadas em formato .dbf ${ }^{3}$ para o Excel.

A estatística descritiva da população e das amostras da área de estudo, assim como as análises de variância e teste de normalidade dos dados foi realizado no software Minitab 15, utilizando-se as ferramentas Estatística descritiva, Gráfico de resumo e Teste de normalidade testado ao nível

3 É um formato de compressão de dados usado para banco de dados, que pode ser lido em diversos softwares, entre eles o Excel, Access e ArcGis. de Significância de 5\%, e a análise de variância por meio da ferramenta One-Way.

\section{Planejamento da amostragem e definição das variáveis respostas}

O shape da área de estudo (UPA-08) foi dividido em 56 unidades primárias de 25 ha, onde cada subpopulação correspondeu a uma área quadrada de $500 \mathrm{~m}$ de lado. Em cada unidade primária foi alocado um conglomerado. A estrutura amostral conglomerada possui uma forma cruzada, onde as oito subparcelas possuem a forma retangular orientadas na estrutura do inventário segundo as direçóes Norte-Sul e LesteOeste. As subparcelas foram tomadas com o tamanho de 30, 40, 50, 60 e 70 metros de comprimento por 20 metros de largura, cujas áreas variam de $600 \mathrm{~m}^{2}$ a $1400 \mathrm{~m}^{2}$.

Esta esquematizaçáo, com relação à variaçáo do tamanho da subparcela, possibilitou obter 5 (cinco) diferentes tamanhos de área de conglomerados. Essas áreas de conglomerados geraram um gráfico por meio do cálculo dos respectivos coeficientes de variação (eixo das ordenadas), tendo-se como abscissa os 5 (cinco) tamanhos de subparcela, e sobre a curva obtida, a partir do Método da Curvatura Máxima descrito por Federer (1955), foi obtido o melhor tamanho de subparcela. Dessa forma, uma vez definido o tamanho ótimo da subparcela esta foi mantida fixa, ou seja, seu tamanho permanece constante. E em seguida procedeu-se a análise de 5 (cinco) diferentes distâncias de subparcelas, ao ponto central do conglomerado e entre as subparcelas, que foram tomadas com 30, 40, 50, 60 e 70 metros, a fim de determinar a distância ideal entre as subparcelas.

Para estudar o tamanho ótimo da subparcela e a distância ideal desta ao centro do conglomerado foram consideradas as seguintes variáveis respostas: (i) VT: Volume de madeira com casca das árvores com DAP $\geq 30 \mathrm{~cm}$ considerando as 77 espécies ocorrentes na área; (ii) VO: Volume das 10 espécies mais volumosas da área; e (iii) VC: Volume das espécies com mercado internacional garantido ou com potencial de mercado.

As espécies com maior volume e ocorrência de indivíduos são Cupiuba (Goupia spp.), Castanheira (Bertholletia excelsa Humb. \& Bonpl.), Tachi (Tachigali spp.), Burangica (Sloanea spp.), Casca seca (Licania spp.), Melancieiro (Alexa spp.), Faveira (Parkia spp.), Quaruba (Voshysia spp.), Angelim (Dinizia spp.), Matamata (Eschweleira spp.). As espécies com mercado internacional garantido ou com potencial de mercado são Maçaranduba (Manilkara spp.), Angelim (Dinizia $s p p$.), Jatobá (Hymenaea spp.), Faveira (Parkia spp.), Cumaru (Dipteryx spp.), Piquia (Caryocar spp.), Cupiuba (Goupia $s p p$.), Breu (Protium spp.), Timborana (Parkia spp.), Matamata (Eschweleira spp). 


\section{Análise estatística}

A análise dos dados consistiu em calcular, inicialmente, os volumes das árvores a partir da equação de volume de Spurr (1952), o que possibilitou obter a quantificação volumétrica para a população e para as amostras (área amostral de $600 \mathrm{~m}^{2} \mathrm{a}$ $\left.1400 \mathrm{~m}^{2}\right)$. Considerando que a população possui 56 unidades primárias $(\mathrm{N}=56)$ com 8 (oito) subparcelas por unidade secundária $(\mathrm{m}=8)$ totalizando 448 subparcelas $(\mathrm{M}=448)$ e a amostra total possui 30 unidades secundárias $(n=30)$.

Para a escolha das unidades amostrais realizou-se um sorteio aleatório com reposição através do Programa Bioestat $5.0 \mathrm{O}$ experimento tem como tratamento os conglomerados e como repetição as subparcelas.

$\mathrm{Na}$ primeira análise de variância foi considerada a unidade conglomerada com subparcela de tamanho igual a $600 \mathrm{~m}^{2}$, a segunda análise de variância foi realizada para o conglomerado com subparcela de tamanho igual a $800 \mathrm{~m}^{2}$, e assim sucessivamente, por meio do incremento em área de $200 \mathrm{~m}^{2}$, até atingir um tamanho final de subparcela igual a $1400 \mathrm{~m}^{2}$, o que permitiu testar 5 (cinco) tamanhos diferentes de subparcelas.

Para cada tamanho de subparcela foram realizadas 3 (três) análises de variância correspondentes as variáveis resposta VT, VO e VC, assim como para as distâncias, totalizando 30 análises de variâncias. As análises de variância para os conglomerados considerando os 5 (cinco) tamanhos e as 5 (cinco) diferentes distâncias de subparcelas, foram processadas de acordo com a concepçáo de uma amostragem em dois estágios, com seleção mista e grandezas iguais, conforme apresentado em Péllico Netto e Brena (1997).

Foi calculado o valor médio esperado por conglomerado (VMEPC), utilizando soma de cada conglomerado divido por $\mathrm{n}(\mathrm{n}=30)$, em seguida obteve o valor médio esperado por subparcela (VMEPS) dividindo-se o VMEPC por $\mathrm{m}(\mathrm{m}=8)$.

Para obtenção da variância entre as subparcelas $\left(\hat{\sigma}_{\mathrm{e}}^{2}\right)$, procedeu-se da seguinte forma, obteve-se a variância entre as subparcelas através da fórmula $\hat{\sigma}_{\mathrm{e}}^{2}=\frac{\hat{\mathrm{M} E}-\mathrm{QM} D}{\mathrm{~m}}$, em que QM̂E: quadrado médio entre os conglomerados; $\hat{\mathrm{M} D}$ : quadrado médio dentro dos conglomerados; m: número de subparcelas por conglomerado. Em seguida as variâncias entre e dentro das subparcelas foram somadas $\hat{\sigma}^{2}=\hat{\sigma}_{\mathrm{e}}^{2}+\hat{\sigma}_{\mathrm{d}}^{2}$, em que $\hat{\sigma}^{2}$ : variância total das subparcelas. Para hectarizar os dados da variância usou um fator de correção $k$, dividindo-se a área de 1 hectare em metros quadrados pela área da subparcela em metros quadrados, e em seguida multiplicou-se esse fator $\mathrm{k}$ pela variância obtida.

O coeficiente de correlação intraconglomerados foi obtido através da fórmula para populaçóes finitas

$$
\hat{\delta}=\frac{(\mathrm{n}-1) \mathrm{m} \cdot \mathrm{QME}-(\mathrm{nm}-1) \hat{\sigma}^{2}}{(\mathrm{~nm}-1) \cdot(\mathrm{m}-1) \hat{\sigma}^{2}} \text {, o coeficiente de }
$$

correlação intraconglomerados mostrará se a área amostrada está mais apropriada para um processo de amostragem por conglomerados por estratificaçáo, caso $\hat{\delta}$ seja maior que 0,4 , isso indica que a área é mais apropriada para o processo de estratificação, este coeficiente também foi usado para se determinar o número de subparcelas ideal (Queiroz et al. 2011).

Devido não haver até a conclusão desta pesquisa uma equação desenvolvida especificamente para populaçóes finitas em estudo de processo de amostragem por conglomerados, usou-se para o cálculo do número de subparcela ideal a fórmula desenvolvida oor Péllico Netto e Brena (1997), para populações infinitas, $\mathrm{m}=\sqrt{\frac{\mathrm{C}_{2}}{\mathrm{C}_{1}}\left(\frac{1-\delta}{\delta}\right)}$. Como não houve análise de custos de instalaçáo de parcelas e deslocamento entre parcelas na presente pesquisa, foi utilizado $\mathrm{C} 2 / \mathrm{C} 1=3$, este foi o mesmo valor usado pelo autor em inventário florestal realizado na Amazônia equatoriana. Queiroz et al. (2011) adverte que o uso da fórmula de Péllico Netto e Brena para populaçôes finitas é muito perigoso, pois quando $\delta$ tende a zero o $m$ tenderá a um valor infinito.

A variância da média foi obtida através da fórmula descrita por Queiroz et al. (2011) para populaçóes finitas $\mathrm{V}(\overline{\overline{\mathrm{y}}})=\left(1-\mathrm{f}_{1}\right) \frac{\hat{\sigma}_{1}^{2}}{\mathrm{n}}+\mathrm{f}_{1}\left(1-\mathrm{f}_{2}\right) \frac{\hat{\sigma}_{2}^{2}}{\mathrm{~m} \cdot \mathrm{n}}$ em que $\mathrm{f}_{1}$ : fração amostral $\mathrm{n} / \mathrm{N} ; \mathrm{f}_{2}$ : fração amostral $\mathrm{m} / \mathrm{M} ; \hat{\sigma}_{1}^{2}$ : variância estimada entre os valores médios dos conglomerados; $\hat{\sigma}_{2}^{2}$ : média das variâncias estimadas das subparcelas dentro dos conglomerados; $\mathrm{N}$ : número total de conglomerados; n: número de conglomerados amostrados; M: número total de subparcelas; m: número de subparcelas por conglomerado, através desta foi gerado o erro padrão da média, para em seguida obterem-se os intervalos de confiança e limite de erro para as variáveis respostas VT, $\mathrm{VO}$ e VC.

O Limite de Erro (LE) pode ser definido como a semi-amplitude do intervalo de confiança $\left(\frac{\operatorname{t.s}(\overline{\mathrm{y}})}{\overline{\bar{y}}}\right)$, e representado como porcentagem da média, conforme a equaçáo $L E=\frac{\operatorname{t.s}(\overline{\mathrm{y}})}{\overline{\bar{y}}} \cdot 100$. Nesta pesquisa o LE é usado para a mostrar que a precisão estatística pode ser afetado pela variação do tamanho de área das subparcelas, assim como pode ser utilizado para obter o número de conglomerados amostrados (n). O valor de $\mathrm{t}=2,72$ foi encontrado com auxilio da tabela $\mathrm{t}$ de Student, com nível de significância $\alpha=0,05$, em que t: valor tabelado de $\mathrm{n}-1$ graus de liberdade ao nível de significância de $\alpha=0,05 ; \mathrm{s}(\overline{\mathrm{y}})$ : desvio padrão da média; $\overline{\overline{\mathrm{y}}}$ : média amostral. 
Para se determinar o coeficiente de variação $(\mathrm{CV})$ primeiro encontrou-se o desvio padrão que foi obtido através da raiz quadrada da variância encontrada, e em seguida dividiu-se desvio padrão pelo VMEPS em hectare, e multiplicou-se o resultado por 100 para gerar um índice relativo que foi usado para se determinar o tamanho ideal de parcela, usando a metodologia de Federer (1955).

No processo de amostragem por conglomerados, Queiroz (1977) descreve que, para que uma população seja considerada infinita é necessário que $\frac{N-n}{N} \geq 0,95$, em que $\mathrm{N}$ : número de unidades primárias ou conglomerados alocados na área de estudo; n: número de unidades secundárias amostradas da área de estudo. Essa fórmula foi usada para determinar a qual tipo de populaçáo pertence os dados estudados.

Segundo Cochran (1965), esses fatores atuam diretamente sobre a variância e o erro padrão como parâmetro de correçấo das populaçôes finitas - CPF, sendo que, na prática, as CPF's podem ser ignoradas, quando a fração amostral não exceder $5 \%$ e, em muitos casos, até mesmo quando seu valor chegar a $10 \%$. O autor adverte ainda que, a conseqüência de ignorar as correçôes é a superestimaçáo do erro padrão da estimativa $\overline{\mathrm{y}}$.

O mesmo procedimento foi usado para se determinar a distância ideal do centro do conglomerado até as parcelas e entre as subparcelas.

\section{RESULTADOS E DISCUSSÃO}

Devido à fração de amostragem $\left(\frac{\mathrm{n}}{\mathrm{N}}=0,53\right)$ para a população estudada ter apresentado valor superior a 5\%, justifica-se o uso do fator de correção para populaçôes finitas $\left(\frac{N-n}{N}\right)$, o qual apresentou valor igual a $0,46, \log$ o a população deve ser classificada como finita. Dessa forma, os cálculos para estimativas dos parâmetros populacionais a partir das amostras foram baseados neste tipo de populaçáo para evitar segundo Cochran (1965), a superestimação sobre o erro padrão dos dados estudados, os trabalhos realizados por Queiroz (1977) corroboram com o autor anteriormente citado e com os resultados obtidos nesta pesquisa.
A média volumétrica para a populaçáo encontra-se em torno de $57 \mathrm{~m}^{3}$ ha $^{-1}$, essa média corrobora com outros trabalhos realizados na regiáo pela FAO e SUDAM entre as décadas de 50 e 60 (Sudam 1974).

$\mathrm{Na}$ Tabela 1, pode-se observar que a média amostral, para todos os tamanhos de área de subparcela, está próximo do valor da média populacional e que a mesma para a variável de estudo (VT) encontra-se dentro do intervalo de confiança para um teste de normalidade Komogorov-Smirnov com $\alpha=0,01$. Ainda com relaçáo ao teste de normalidade pode-se observar, na Tabela 1, que a variável resposta VT apresenta distribuição normal para todos os tamanhos de subparcela mantendo a precisão estatística dos dados amostrados. Entretanto para a variável resposta $\mathrm{VO}$ obteve-se distribuição normal dos dados apenas a partir do tamanho de $1000 \mathrm{~m}^{2}$, e a variável VC apenas a partir do tamanho de $1200 \mathrm{~m}^{2}$. Justifica-se a falta de normalidade dos dados para a maioria dos tamanhos de área de subparcelas, das variáveis respostas: $\mathrm{VO}$ e VC, devido ao reduzido número indivíduos e alta heterogeneidade volumétrica entre as espécies estudadas.

De acordo com a Tabela 2 são mostrados os limites de erro (LE), obtidos a partir da equaçáo $\mathrm{LE}=\frac{\mathrm{t} \cdot \mathrm{s}(\overline{\mathrm{y}})}{\overline{\bar{y}}} .100$ , para as três variáveis respostas em funçáo do tamanho da subparcela, onde podemos perceber que o limite de erro possui uma relação diretamente proporcional ao aumento do tamanho da subparcela para as variáveis: Volume total das 77 espécies florestais encontradas na área de estudo (VT) e Volume total das 10 espécies florestais comercializadas pela Cikel (VC), enquanto que para a variável Volume total das 10 espécies florestais de maior ocorrência na área de estudo (VO) ocorre tendência de crescimento do limite de erro até o tamanho 20x40 quando então começa a ocorrer oscilaçáo, esse comportamento pode ter sido influenciado pela variação do volume presente nesta variável, pois existem uma variação diamétrica muito grande entre as diferentes espécies florestais existentes na área de estudo.

$\mathrm{O}$ confronto da variaçáo entre os conglomerados e subparcelas dentro dos conglomerados é que revelará a eficiência, em termos de precisão estatística com a aplicaçáo

Tabela 1 - Intervalo de confiança da variável volume total (VT) para cinco diferentes tamanhos de subparcela.

\begin{tabular}{|c|c|c|c|c|c|c|c|c|c|c|c|}
\hline Subparcela & k & $\bar{x}$ & $\bar{x} \cdot h a^{-1}$ & $S^{2}$ & $\mathrm{~S}^{2} \cdot \mathrm{ha}^{-1}$ & $\mu$ & $\mu \cdot h a^{-1}$ & $\sigma$ & $\sigma . h a^{-1}$ & $\begin{array}{l}\text { Intervalo de } \\
\text { confiança }\end{array}$ & Valor $p$ \\
\hline $20 \times 30$ & 16,7 & 3,81 & 63,43 & 32,87 & 9131,46 & 3,5 & 57,96 & 23,21 & 6472,75 & $55,76 \leq X \leq 71,10$ & 0,014222 \\
\hline $20 \times 40$ & 12,5 & 5,31 & 66,41 & 46,54 & 7271,16 & 4,6 & 57,70 & 33,00 & 5156,56 & $56,91 \leq X \leq 75,91$ & 0,086893 \\
\hline $20 \times 50$ & 10 & 6,48 & 64,81 & 50,63 & 5062,81 & 5,8 & 57,70 & 43,96 & 4396,30 & $54,30 \leq X \leq 75,33$ & $>0,15$ \\
\hline $20 \times 60$ & 8,3 & 7,47 & 62,24 & 60,07 & 4171,65 & 6,9 & 57,55 & 54,61 & 3761,90 & $50,84 \leq X \leq 73,64$ & $>0,15$ \\
\hline $20 \times 70$ & 7,1 & 8,42 & 60,15 & 70,04 & 3573,35 & 8,1 & 68,20 & 68,20 & 3437,75 & $48,18 \leq X \leq 72,11$ & $>0,15$ \\
\hline
\end{tabular}

Em que K: fator proporcionalidade; $\quad \bar{x}$ : média amostral; $\bar{x} . h^{-1}:$ média amostral por hectare; $\mathrm{S}^{2}:$ variância amostral; $\mathrm{S}^{2}$.ha- $\mathrm{H}^{-1}$ : variância amostral por hectare; $\mu$ : média paramétrica da população; $\mu . h^{-1}$ : média paramétrica da população por hectare; $\sigma$ : variância populacional; $\sigma \cdot$ ha $^{-1}$ : variância populacional por hectare; Valor p: teste de normalidade Komogorov-Smirnov. 
Tabela 2 - Limite de erro em porcentagem as três variáveis respostas em função do tamanho de subparcela.

\begin{tabular}{cccc}
\hline \multirow{2}{*}{ Tamanho de subparcela } & \multicolumn{3}{c}{ Limite de erro (\%) } \\
\cline { 2 - 4 } & VT & V0 & VC \\
\hline $20 \times 30$ & 31 & 43 & 44 \\
$20 \times 40$ & 35 & 49 & 49 \\
$20 \times 50$ & 38 & 48 & 52 \\
$20 \times 60$ & 41 & 51 & 56 \\
$20 \times 70$ & 42 & 49 & 60 \\
\hline
\end{tabular}

Em que VT: Volume total das 10 espécies de maior volume, V0: Volume Total das 10 espécies de maior ocorrência na área e VC: Volume Total das 10 espécies de maior comercialização pela empresa Cikel Brasil Verde Madeiras Ltda.

da amostragem. A amostragem por conglomerados será mais precisa quanto maior for o valor do componente de variância entre as subparcelas dentro dos conglomerados $\left(S_{d}^{2}\right)$ e menor o componente de variância entre os conglomerados $\left(S_{e}^{2}\right)$. Depreende-se que o processo por conglomerados é recomendável para florestas que revelam, em termos das variáveis respostas escolhidas, alta variação dentro dos conglomerados e relativa uniformidade entre os conglomerados (Queiroz 1977).

$\mathrm{Na}$ Figura 2, pode-se observar a tendência de variabilidade dos valores do coeficiente de variação em função do tamanho da subparcela para as três variáveis respostas. $\mathrm{O}$ tamanho de subparcela considerado ideal, com localização centralizada na regiāo de máxima curvatura, correspondeu à soma do total de oito unidades básicas (subparcelas), cuja área abrange 0,10 ha. Conforme descrito por Queiroz et al. (2011) existe uma relação inversamente proporcional da variabilidade dos valores do coeficiente de variação em função do tamanho das

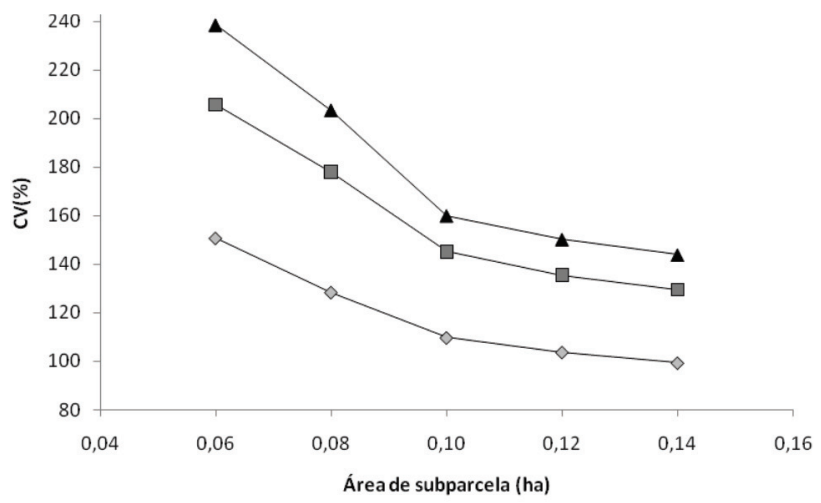

$\checkmark$ Volume Total das 77 espécies da área de estudo (VT).

$\neg \square$ Volume das 10 espécies de maior volumetria na área de estudo (VO).

\-Volume total das 10 espécies mais comercializadas pela Cikel (VC).

Figura 2 - Coeficiente de variação em função do tamanho da subparcela. VT: Volume total das 77 espécies florestais da área de estudo; V0: Volume das 10 espécies florestais de maior ocorrência na área de estudo; VC: Volume das 10 espécies florestais mais comercializadas pela empresa Cikel Brasil Verde Madeiras Ltda. subparcelas, ou seja, à medida que se aumenta o tamanho da subparcela diminui o valor do coeficiente de variação.

Com base na Figura 3, observa-se a variabilidade do coeficiente de correlação intraconglomerado em função do tamanho da subparcela para as três variáveis respostas, podendo-se verificar gráfico que existe uma relação diretamente proporcional da variabilidade do coeficiente de correlação intraconglomerado em função do tamanho das subparcelas, ou seja, à medida que aumenta o tamanho da subparcela cresce o valor do coeficiente de correlação intraconglomerado e tende posteriormente a estabilização. Os valores dos coeficientes de correlação intraconglomerado, considerando um tamanho de subparcela ideal de 0,10 ha, para as três variáveis foram bem abaixo de 0,4 , indicando ser um tamanho de subparcela adequado para a área estudada.

A estrutura conglomerada cruzada com subparcelas de tamanho igual a 0,10 ha, para as três variáveis respostas, apresentou valores para o coeficiente de correlaçáo intraconglomerado que variaram de 0,16 a 0,12 , e que de acordo o critério utilizado por Péllico Netto e Brena (1997) atende o limite aceitável, que é de $0 \leq \rho \leq 0,4$, para aplicação em inventários florestais.

$\mathrm{Na}$ Figura 4 é apresentada a variabilidade do número de subparcelas em função do tamanho da subparcela para as três variáveis respostas. Observa-se no gráfico que à medida que aumenta o tamanho da subparcela diminui a quantidade de subparcelas. A Tabela 3 mostra que os valores de número de subparcela variam de 4 a 7 subparcelas para qualquer tamanho de subparcela, enquanto que para a área de 0,10 ha os valores variam entre 4 e 5 subparcelas para as VT, VO e VC, logo

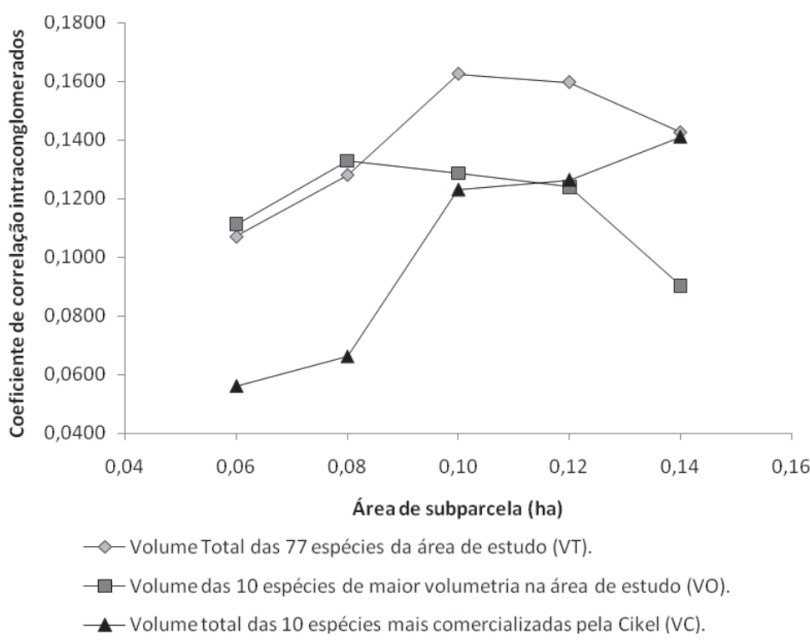

Figura 3 - Coeficiente de correlação intraconglomerado em função do tamanho da subparcela. VT: Volume total das 77 espécies florestais da área de estudo; V0: Volume das 10 espécies florestais de maior ocorrência na área de estudo; VC: Volume das 10 espécies florestais mais comercializadas pela empresa Cikel Brasil Verde Madeiras Ltda. 


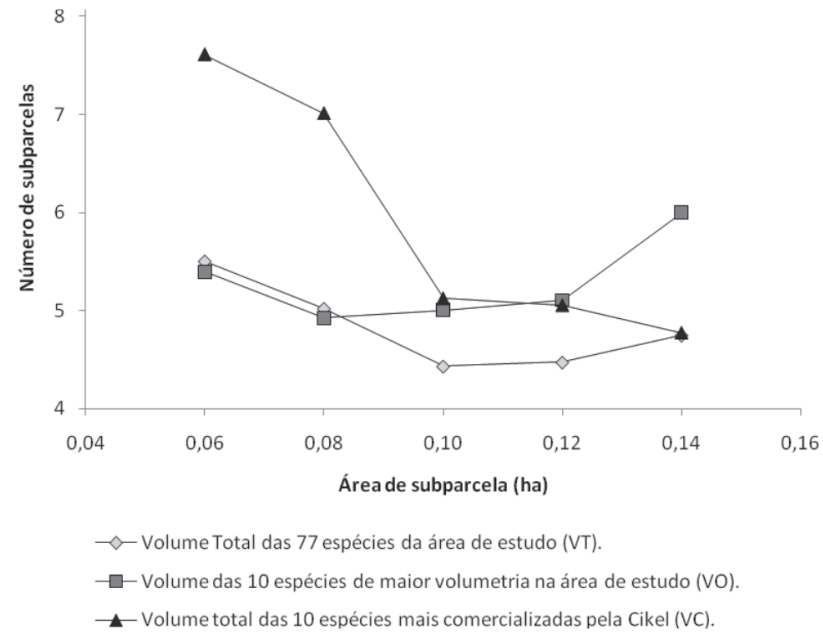

Figura 4 - Variação do número de subparcelas em função da área de subparcela. VT: Volume total das 77 espécies florestais da área de estudo; V0: Volume das 10 espécies florestais de maior ocorrência na área de estudo; VC: Volume das 10 espécies florestais mais comercializadas pela empresa Cikel Brasil Verde Madeiras Ltda.

é possível afirmar que o uso de 8 (oito) subparcelas de 0,10 ha, com estrutura conglomerada cruzada, não é o ideal para a área de estudo.

Os resultados permitem inferir que, apesar do número ideal de subparcelas para as variáveis VT, VO e VC estejam próximo de 5 (cinco), uma estrutura retangular com 6 (seis) subparcelas seria mais fácil de ser instalada no campo, sendo este o número de subparcelas recomendável para um tamanho de subparcela igual a 0,10 ha.

A distância entre as subparcelas e o ponto central do conglomerado, e o tamanho da subparcela, definem o valor do coeficiente de correlação intraconglomerado. Esses parâmetros aliados ao custo de implantação e medição dos conglomerados, evidentemente, são os instrumentos para planejar a estrutura conglomerada ideal (Queiroz 1977).

De acordo com a Tabela 4, na qual mostra o limite de erro em função do distanciamento das subparcelas em relação ao ponto central do conglomerado e entre as subparcelas, pode-se observar que o limite de erro aumenta com o distanciamento até a distância de 60 metros e diminui na distância de 70

Tabela 3 - Variação do número de subparcelas em função do tamanho de subparcela.

\begin{tabular}{cccc}
\hline Tamanho de subparcela & VT & VO & VC \\
\hline $20 \times 30$ & 5 & 5 & 7 \\
$20 \times 40$ & 5 & 4 & 7 \\
$20 \times 50$ & 4 & 5 & 5 \\
$20 \times 60$ & 4 & 5 & 5 \\
$20 \times 70$ & 5 & 6 & 4 \\
\hline
\end{tabular}

Em que VT: Volume total das 10 espécies de maior volume, V0: Volume Total das 10 espécies de maior ocorrência na área e VC: Volume Total das 10 espécies de maior comercialização pela empresa Cikel Brasil Verde Madeiras Ltda.
Tabela 4 - Limite de erro em função da distância do ponto central do conglomerado até as subparcelas e entre as subparcelas.

\begin{tabular}{cccc}
\hline \multirow{2}{*}{ Distância } & \multicolumn{3}{c}{ Limite de erro (\%) } \\
\cline { 2 - 4 } & VT & V0 & VC \\
\hline $30 m$ & 43 & 45 & 54 \\
$40 m$ & 37 & 44 & 52 \\
$50 m$ & 39 & 48 & 56 \\
$60 m$ & 41 & 48 & 57 \\
\hline $70 m$ & 37 & 45 & 59
\end{tabular}

Em que VT: Volume total das 10 espécies de maior volume, V0: Volume Total das 10 espécies de maior ocorrência na área e VC: Volume Total das 10 espécies de maior comercialização pela empresa Cikel Brasil Verde Madeiras Ltda.

metros para as variáveis $\mathrm{VT}$ e $\mathrm{VO}$, isso pode ser explicado pelo fato de que na distância 70 metros a área da unidade secundária é muito próxima da área da unidade primária, enquanto que para a variável VC o limite de erro continua a apresentar tendência de crescimento. Recomenda-se que apesar diminuiçáo do limite de erro para as variáveis VT e VO distâncias maiores que 50 metros para um tamanho de subparcela de 0,10 ha, pois os limites de erro destas variáveis para as distâncias 50 e 70 metros são muito próximos.

Na Figura 5 é apresentada a variabilidade do coeficiente de correlação intraconglomerado em funçáo da distância das subparcelas ao centro do conglomerado e entre as subparcelas para as três variáveis respostas. É possível observar que todas as distâncias atendem a condição $\rho \leq 0,4$ proposta por Péllico Netto e Brena (1997) para a instalaçáo processos de amostragem por conglomerado e que à medida que a distância aumenta o coeficiente de correlação intraconglomerado tende a diminuir até atingir a estabilização. Os valores do coeficiente de correlaçáo intraconglomerado, para as três

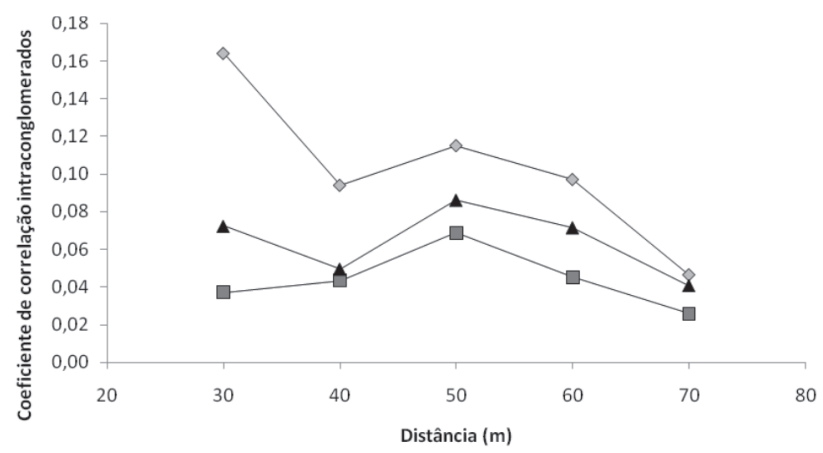

$$
\begin{aligned}
& \square \text { Volume total das } 77 \text { espécies da área de estudo (VT) } \\
& \square \text { - Volume total das } 10 \text { espécies de maior volumetria na área de estudo (VO) } \\
& \square \text { Volume total das } 10 \text { espécies mais comercializadas pela Cikel (VC) }
\end{aligned}
$$

Figura 5 - Variação do coeficiente de correlação intraconglomerado em função da distância de subparcela em relação ao ponto central do conglomerado e entre subparcelas. VT: Volume total das 77 espécies florestais da área de estudo; V0: Volume das 10 espécies florestais de maior ocorrência na área de estudo; VC: Volume das 10 espécies florestais mais comercializadas pela empresa Cikel Brasil Verde Madeiras Ltda. 
variáveis respostas, considerando uma distância de $50 \mathrm{~m}$ das subparcelas ao centro do conglomerado, para um tamanho de subparcela de $0,10 \mathrm{ha}$, apresentaram os seguintes resultados: $\mathrm{VT}=0,115, \mathrm{VO}=0,068$ e $\mathrm{VC}=0,086$. Estes valores denotam que o uso de subparcelas com tamanho de 0,10 ha e distantes $50 \mathrm{~m}$ do centro do conglomerado até as subparcelas e entre as subparcelas é uma opção viável, pois estão bem abaixo de $\rho \leq 0,4$.

Os valores dos coeficientes correlação intraconglomerado para o tamanho de subparcela de 0,10 ha, para as três variáveis respostas, e considerando as 5 (cinco) diferentes distâncias estudadas, apresentaram valores no máximo igual a 0,16 , estando abaixo do limite de 0,4 estabelecido por Péllico Netto e Brena (1997), dessa forma pode-se inferir que qualquer uma das distâncias estudadas para o tamanho de subparcela 0,10 ha pode ser viável para estimar os parâmetros da pesquisa, porém, conforme descrito por Queiroz et al. (2011) à medida que aumenta a distância entre as subparcelas e o ponto central do conglomerado, o coeficiente de correlação intraconglomerado decresce até que a variação entre os conglomerados atinja o seu limite mínimo. Esta situação faz com que o número de subparcelas atinja o seu valor ideal, resultando, evidentemente, na medição de um menor número de conglomerados, tornando dessa forma, o processo de amostragem, mais prático uma vez que a homogeneidade já foi alcançada.

Na concepção de Queiroz et al. (2011), as experiências na realização de inventários florestais na Amazônia recomendam que a distância das subparcelas ao centro do conglomerado, não deve ser inferior a $50 \mathrm{~m}$, a fim de se evitar autocorrelação, ou seja, homogeneidade entre as subparcelas. Ressalta-se, dessa forma, que para a área de estudo a distância ideal é de $50 \mathrm{~m}$ do centro do conglomerado até as subparcelas e entre as subparcelas para um tamanho de subparcela de 0,10 ha, pois distâncias maiores implicarão no aumento do numero de subparcelas, conseqüentemente elevando os custos de implantação dos conglomerados para o processo de amostragem.

Em relação à variabilidade do número de subparcelas ideal em função da distância das subparcelas ao centro do conglomerado até as subparcelas e entre as subparcelas para as três variáveis respostas. Observa-se que existe uma relação diretamente proporcional entre distância e o número de subparcelas para a variável resposta VT, ou seja, à medida que a distância aumenta o número de subparcelas também aumenta. Enquanto que para as variáveis $\mathrm{VO}$ e $\mathrm{VC}$ isto ocorre somente a partir da distância $50 \mathrm{~m}$. É possível observar na Tabela 5 que na distância $50 \mathrm{~m}$ o número de subparcelas variou de $6 \mathrm{a}$ 7 para as três variáveis respostas, dessa forma, uma estrutura conglomerada retangular com 6 (seis) subparcelas é mais adequado. Entretanto, baseado em experiências de campo, podemos afirmar que a instalação de mais 2 (duas) subparcelas
Tabela 5 - Variação do número de subparcelas em função da distância.

\begin{tabular}{cccc}
\hline Distância & VT & V0 & VC \\
\hline $30 \mathrm{~m}$ & 5 & 10 & 7 \\
$40 \mathrm{~m}$ & 6 & 9 & 9 \\
$50 \mathrm{~m}$ & 6 & 7 & 7 \\
$60 \mathrm{~m}$ & 9 & 9 & 7 \\
$70 \mathrm{~m}$ & 12 & 12 & 10 \\
\hline
\end{tabular}

Em que VT: Volume total das 10 espécies de maior volume, V0: Volume Total das 10 espécies de maior ocorrência na área e VC: Volume Total das 10 espécies de maior comercialização pela empresa Cikel Brasil Verde Madeiras Ltda.

não aumentaria demasiadamente os custos e não alteraria a precisão estatística das estimativas, assim como facilitaria a instalação das parcelas no campo, logo uma estrutura cruzada com 8 (oito) subparcelas pode ser usada sem prejuízo das estimativas para as três variáveis respostas objeto deste estudo. Vale ressaltar, ainda, que fórmula usada para obter o número ideal de subparcela foi desenvolvida por Péllico Netto (1977) para populaçóes infinitas, o que pode ter influenciado para a redução do número ideal de subparcelas.

\section{CONCLUSÕES}

Infere-se dos resultados que o tamanho ideal da subparcela é de 0,10 ha e que o tamanho de unidade amostral 0,80 ha é eficiente para estimar a variável resposta objeto deste estudo, para a área de floresta ombrófila densa do alto rio Pacajá, estudada a partir do processo de amostragem por conglomerados.

Conclui-se também que a distância ideal do centro do conglomerado até as subparcelas e entre as subparcelas é de $50 \mathrm{~m}$, para um tamanho de subparcela de 0,10 ha.

Conclui-se, também, que uma estrutura conglomerada cruzada com 8 (oito) subparcelas, tendo como variável resposta o Volume total das 10 espécies de maior volume (VT), Volume Total das 10 espécies de maior ocorrência na área (VO) e o Volume Total das 10 espécies de maior comercialização (VC) é mais recomendável para trabalhos de campo.

\section{BIBLIOGRAFIA CITADA}

Brena, D. A. 1996. Proposição de um sistema de inventário florestal nacional para o Brasil. Revista Ciência Florestal, 6: 109-127.

Cavalcanti, F.J.B.; Machado, S.A.; Hosokawa, R.T. 2009. Tamanho de unidade de amostra e intensidade Amostral para espécies comerciais da Amazônia. Revista Floresta, 39: 207-214.

Cochran, W.G. 1965. Técnicas de Amostragem (1ª ed.). Rio de Janeiro, Rio de Janeiro, Brasil: Fundo de cultura. 555 pp.

Federer, W.T. 1955. Experimental Design - theory and application. New York: Macmillan.

Ferreira, J.E.; Silva, S.D.B.; Lages, S.M.C. 2009. Plano de Manejo Florestal Sustentável de Uso Múltiplo Empresarial. Belém, Pará, Brasil: CIKEL BRASIL VERDE MADEIRAS LTDA-AMF MARTINS AGROPECUÁRIA S/A. 
Higuchi, N.; Santos, J.D.; Jardim, F.C.S. 1982. Tamanho de parcela amostral para inventários florestais. Acta Amazonica, 12: 91-103.

Lima, J. F.; Peixoto, C.P.; Ledo, C.A.S.; Faria, G.A. 2007. Tamanho ótimo de parcela para experimentos com plantas de mamoeiro em casa de vegetação. Ciência e Agrotecnologia, 31: 1411-1415.

Mello, J.M.; Scolforo, J.R.S. 2000. Análise comparativa de procedimentos de amostragem em uma remanescente de floresta estacional semidecídua montana. Revista Árvore, 24: 55-62.

Muniz, J.A.; Aquino, L.H.; Simplicio, E.; Soares, A.R. 2009. Estudo do tamanho de parcelas experimentais em povoamentos de Eucalyptus grandis Hill, usando parcelas lineares. Ciência e agrotecnologia, 33: 1002-1010.

Oliveira, R.L.; Muniz, J.A.; Andrade, M.J.B.; Reis, R.L. 2009. Precisão experimental em ensaios com a cultura do feijão. Ciência e Agrotecnologia, 33: 113-119.

Péllico Netto, S.; Brena, D.A. 1997. Inventário Florestal. Curitiba: Editorado pelos autores.

Queiroz, W.T.; Péllico Netto, S.; Valente, M.D.R.; Pinheiro, J.G. 2011. Análise Estrutural da Unidade Conglomerada Cruz de Malta na Floresta Nacional do Tapajós, Estado do Pará, Brasil. Revista Floresta, 4: 9-18.

Queiroz, W. T. 1977. Efeitos da variação estrutural em unidade amostral na aplicaçáo do processo de amostragem em conglomerados nas florestas do Planalto do Tapajós. Revista Floresta, 1: 19-23.
Rossetti, A.G. 2002. Influência da área da parcela e do número de repetiçóes na precisáo de experimentos com arbóreas. Pesquisa Agropecuária Brasileira, 37: 433-438.

Radam. 1974. Levantamento de recursos naturais. Ministério das Minas e energia. Brasilia: Departamento Nacional de Produção Mineral.

Sudam. 1974. Levantamentos florestais realizados pela missão FAO na Amazônia (1956-1961). Belém: SUDAM. Divisão de Documentação.

Vianna, A.L.M.; Vidal, E.J.; Gorenstein, M.R.; Batista, J.L.F. 2010. Tamanho ótimo de parcela para estimativa de estoque de carbono da parte aérea lenhosa de fitofisionomias florestais na Amazônia oriental. Revista Floresta, 2: 447-456.

Vieira, M.G.L.; Couto, H.T.Z. 2001. Estudo do tamanho e número de parcelas na Floresta Atlântica do Parque Estadual de Carlos Botelho, São Paulo. Scientia forestalis, 60: 11-20.

Zanon, M.L.B.; Storck, L. 2000. Tamanho ótimo de parcelas experimentais para Eucalyptus saligna Smith em dois estádios de desenvolvimento. Revista Cerne, 6: 104-111.

Recebido em : 07/03/2011

Aceito em : 09/09/2011 